\title{
POÉTICAS DE (ID)ENTIDAD Y PERFORMANCES SECUNDARIAS: SUBJETIVIDADES (A LA DERIVA) EN HOLLYWOOD ${ }^{1}$
}

\author{
Eduardo Barros-Grela, Universidade da Coruña \\ Email: ebarros@udc.es
}

\begin{abstract}
This essay discusses the ways in which performative and interpretative dialectics function within the representational hierarchization of Hollywood film during the 30 's and the 40's. In particular, an emphasis is placed upon Flying Down to Rio (Freeland, 1933), Mexican Spitfire (Goodwins, 1940) and Gilda (Vidor, 1947), in which "stardom" is discussed into their space of hybrid representability. The objective of this analysis is to question the transculturation process that is repressed by the hierarchical connotation of power that is established for Latino spatialities in Hollywood.
\end{abstract}

Keywords: Transculturation, film, Hollywood, subaltern, stardom, spatiality

Title in English: Poetics of (Id)entity and Supporting Performances: (Adrift) Subjectivities in Hollywood

Resumen: Este estudio discute las formas de dialéctica interpretativa y performativa establecidas por la jerarquización representacional en el ámbito del cine hollywoodiense de las décadas de los años 30 y 40. Se estudian, en concreto, los filmes Flying Down to Rio (Freeland, 1933), Mexican Spitfire (Goodwins, 1940) y Gilda (Vidor, 1947) para cuestionar la transculturación reprimida por la connotación jerárquica de poder establecida para las espacialidades latinas en Hollywood, y se problematiza la funcionalidad de la representación de las identidades femeninas y masculinas -o masculinizantes- como maquinaria de ratificación de la estructura social estratificada del Hollywood de la época.

Palabras claves: Transculturación, cine, Hollywood, subalterno, estrella, espacialidad

'...there is a rhetoric of sincerity or authenticity, two qualities greatly prized in stars
because they guarantee, respectively, that the star really is what she or he appears to be.
Whether caught in the unmediated moment of the close-up, uncovered by the
biographer's display of ruthless uncovering, or present in the star's indubitable
sincerity and authenticity, we have a privileged reality to hang on to,
the reality of the star's private self'. the reality of the star's private self'.
R. Dyer

El matiz diferencial añadido que define la distancia conceptual entre una estrella de cine y un 'simple' protagonista reside en la identificación paratextual de la primera con una

Date of reception: 26 April 2010

Date of acceptance: 20 December 2010

Odisea, $n^{\circ} 11$, ISSN 1578-3820, 2010, 315-327 
representación referencial en un espacio otro de la pantalla más allá de la imagen ficcional explícita que la mirada del espectador recrea ante el discurso fílmico. 'En un espacio otro' no implica necesariamente - en el caso sujeto a estudio- 'al otro lado de la pantalla', y es que la propia esencia de la estrella radica en habitar esa zona fronteriza y de deriva, inestable, heterotópica en la que su identidad se manifiesta como subjetividad híbrida y posthumana, propia de un paradigma cíborg, que encarna-corporeíza- las dos proyecciones imaginadas del sujeto tanto desde dentro - como personaje intradiegético de la ficción, en el sentido literal del término, como desde fuera de la pantalla (como personaje de condición intermedia (in-betweenness) del simulacro extradiegético de realidad).

A su vez, la industria cinematográfica -en particular, la de Hollywood- desarrolla plenamente un aparato comercial alrededor de la figura estelar con el objetivo de que la proyección de ésta no quede restringida a una mera acción dramática intratextual, sino que conceptualice esa acción como un recurso aledaño a la maquinaria generadora de capital encapsulada en la imagen antropomórfica generada. Este extenso -e intenso- aparato productor de sujetos -y subjetividades- imaginados configura su campo de acción a partir de un esquema ontológico que va desde la misma representación dramática del personaje hasta la expropiada imagen real de quienes interpretan por vía performativa su papel como estrellas. Su condición inherente se materializa, por lo tanto, a partir de un estado espacial de simulacro que encuentra su hábitat natural en lo que Marc Augé definía como un no-espacio alegórico forjado en las entrañas del show-business, permitiéndole a la estrella configurar mediante una identidad híbrida un mundo que esté al alcance de sus proyecciones fílmicas y de sus vicisitudes estelares fuera del texto fílmico.

Junto a la figura de la estrella nacen y crecen multiformes entidades complementarias que le confieren caracterización identitaria a partir de un modelo de otredad, y que sólo aspiran a cambio a compartir una mínima porción del estrellato que caracteriza a las grandes figuras. Los mencionados agentes complementarios son aquellos actores que ejercen una responsabilidad identitaria como personajes secundarios: son participantes de la creación dramática y son participantes clave en la construcción de la estrella que pasan, no obstante, desapercibidos ante el brillo resplandeciente de las figuras que practican su función de estrellas.

Este estudio pretende discutir las formas de dialéctica interpretativa y performativa que se establecen entre dos niveles distintos dentro de la jerarquización representacional en el ámbito del cine hollywoodiense de la 'edad de oro', y en particular pretende estudiar el particular caso de actantes que profesan su carga de otredad en ese contexto cinematográfico en forma de tres vías de subalternidad: en función de su género (mujeres), de su cultura (latinas) y de su condición (intérpretes de personajes secundarios). Tales manifestaciones de contestación hegemónica se perciben diáfanamente en filmes como Flying Down to Rio (Freeland, 1933), Mexican Spitfire (Goodwins, 1940) o Gilda (Vidor, 1947), en los que Dolores del Río, Lupe Vélez y Margarita Carmen Cansino (Rita Hayworth) respectivamente ejercen de estrellas con un mayor o menor énfasis en sus condicionantes culturales, de clase o de género, y arrastran a su espacio de representabilidad híbrida -por medio de su posicionamiento performativo identitario- a quienes conforman el 'extrarradio' del elenco con el que comparten 'estrellato'. La selección de los textos fílmicos señalada anteriormente responde a un criterio bicéfalo: la transculturación reprimida por la connotación jerárquica 
de poder que se establece entre el episteme latino y el de Hollywood, y la reconfiguración actualizada de la dialéctica propia de la modernidad entre el 'salvaje' y el 'buen salvaje'.

En el primero de estos aspectos, la responsabilidad productora de imaginarios que adquiere la estrella surge a partir de una transgresión connotativa plasmada en la autoproclamación como personaje-otro por parte de los personajes satélite. En el entorno del segundo aspecto, la función identitaria del personaje secundario consiste en realzar los rasgos de la estrella, tanto dentro como fuera de campo, para reafirmar los rasgos axiológicos pertenecientes a una estrella de Hollywood. Un tercer plano de actuación de los personajes secundarios se hallaría, finalmente, en el sistema de identificaciones que responde a una relación implícita aunque directa entre personaje, actor y espectador dentro del mecanismo fílmico. Se establece por lo tanto una relación identitaria complementaria entre las estrellas y los personajes-satélite que las rodean, relación que se problematiza cuando los esos personajes secundarios evolucionan y, en algunos casos, comienzan a adquirir status de estrella y, por lo tanto, se asientan en una configuración aporética de su identidad en la que la dialéctica entre el otro y el uno, se concretizan en su persona. Esos 'subprotagonistas' subalternos cuestionan la validez de los parámetros binarios establecidos y se postulan como subjetividades fragmentadas en la deconstrucción ontológica del imaginario latino en el cine de Hollywood. Hetherington (1997), a partir de su explicación del concepto de 'heterotopía', confirma la validez de esta tensión dialéctica en la reconfiguración identitaria y cultural de las estrellas y los personajes secundarios, que utilizan como referente generalista las relaciones sociales existentes entre una minoría con capacidad crítica de la cultura y la inherencia problemática del personaje secundario como agente contextual de la construcción de la estrella:

[Las heterotopías] organizan un fragmento del mundo social de manera diferente a lo que las rodea. Ese ordenamiento alternativo las marca como Otro y les permite ser consideradas como un ejemplo de forma alternativa de hacer las cosas. [...] Las heterotopías, por lo tanto, revelan que el proceso de ordenamiento social es simplemente eso, un proceso más que una cosa (viii).

En este marco referencial se plasma la condición aporética de la estrella latina desde posiciones tanto intrínsecas como extrínsecas del simulacro actancial propuesto desde Hollywood. Si la problematización de la identificación señalada como estándar tiene cabida en el funcionamiento lineal que afecta a la imagen tradicional de la estrella, lo mismo ocurre con las minorías étnicas (sobre todo aquellas que padezcan el doble silenciamiento de ser latina y ser mujer) que se abren paso a través de los textos fílmicos estadounidenses, ya no como simples referentes de identificación con un determinado público, sino también como referente oblicuo para un espectador distanciado que produce, no obstante, un exotismo en esas estrellas como forma de legitimación de esa otredad que confieren.

Este mecanismo de 'designificación' resulta atractivo para indagar en el papel del personaje secundario en el ámbito conformado por esos tres niveles hermenéuticos que se han propuesto con anterioridad, y genera una serie de problemas ontológicos que repercuten sobre la representabilidad de las subjetividades expuestas. ¿En qué medida el personaje secundario puede producir efectos identificativos en la subjetividad de un sector del pú- 
blico? ¿Se limita su función a representar la abyección del otro como estrategia de énfasis significativo para la propuesta identitaria de la estrella como subjetividad única?

Este estudio se centra en el papel del personaje secundario en relación con la configuración de la estrella latina. El funcionamiento del concepto de performance aplicado a la estrella trata de ahondar en la contradicción ontológica de ésta en su producción identitaria. El fenómeno estelar aglutina performances en dos dimensiones confluyentes: dentro y fuera de la pantalla, en una separación difuminada que tiende a recrear un espacio de frontera indefinido en el que la propia espacialidad de la estrella se impone como subjetividad deconstructora de los parámetros estéticos establecidos.

Flying Down to Rio ofrece la imagen de un personaje (Fred Ayres, interpretado por Fred Astaire) en quien se podrían identificar las características aceptadas como pertenecientes a un secundario, pero su papel intradiegético evoluciona mediante mecanismos de reescritura identitaria y de adquisición de connotaciones 'estelares' para presentarse a sí mismo como una proyección a modo de palimpsesto de su subjetividad, y para afirmar y cuestionar simultáneamente las connotaciones identitarias asumidas por su propia condición como personaje y como actor. La carrera profesional del actor -Fred Astaire- se inicia en cine (tras su afamado paso por musicales de Broadway y Londres) con papeles de una relativa relevancia, y su trabajo en Flying Down to Rio es muestra de su incipiente evolución de su meteórica carrera. Su participación como actor de reparto implica una condición de tránsito hacia el microcosmos de la pantalla fílmica, y así se hace eco de ello la industria cinematográfica, que apuesta en el tráiler oficial del texto fílmico por centrar sus atractivos en la pareja de baile 'americana', Fred y Ginger, a pesar de encontrarse indudablemente situados en segundo término en la trama. Ninguno de los dos personajes principales, Dolores del Río y Gene Raymond, son mencionados. Así, un personaje interpretado por un actor estadounidense, cuya relevancia narrativa es secundaria, se alza con el protagonismo publicitario dirigido en primera instancia al público, y logra someter al estrellato de Dolores del Río a una subalternidad 'ejemplarizante' en el subconsciente del público americano, que ve en Fred Astaire una actuación de los valores fundamentales que el espectador desea encontrar en las representaciones de su mismedad. La descentralización que se había producido al afirmar a mujeres latinas como sujetos actantes en la producción identitaria estimulada por la gran pantalla, se desplaza de nuevo para desterritorializar a esta figura hacia el margen (espacial, político y estético) y reterritorializar al actor hombre y blanco hacia una posición discursiva hegemónica (a ambos lados de la pantalla). Tanto el texto que acompaña al primer tráiler oficial de la obra como los carteles que la publicitaron son muy esclarecedores: 'The sky's the limit!.... in this musical extravaganza! An airomance staged above the clouds, a million miles from care! 200 beauties and a host of Stars will take you... Flying Down to Rio. You'll always remember the gorgeous girls' ${ }^{2}$. Resulta evidente que la propuesta actancial aquí expresada implica un posicionamiento del hombre estadounidense como sujeto que dirige su mirada hacia el objeto exótico de una figura de mujer latina. Esa mirada apropiacionista se hace evidente en los carteles publicitarios de la obra, en los que la figura blanca masculina (también la blanca femenina) aparece en actitud displicente 2 The New York Times. <http://movies.nytimes.com/movie/17969/Flying-Down-to-Rio/trailers>. Acceso:
12/08/2008

Odisea, $n^{\circ} 11$, ISSN 1578-3820, 2010, 315-327 
-aunque condescendiente- y como ejecutora de una identidad de los observados que ya le pertenece. Cita Linda Williams al crítico francés Jean Clair para afirmar que 'the gaze is an erection of the eye' (14). Tal erección del ojo se manifiesta en los posters de Flying Down to Rio a través de la propia maquetación y distribución de imágenes, en las que aparecen claramente los sujetos actantes frente a las figuras reificadas (figs. 1 y 2$)^{3}$.

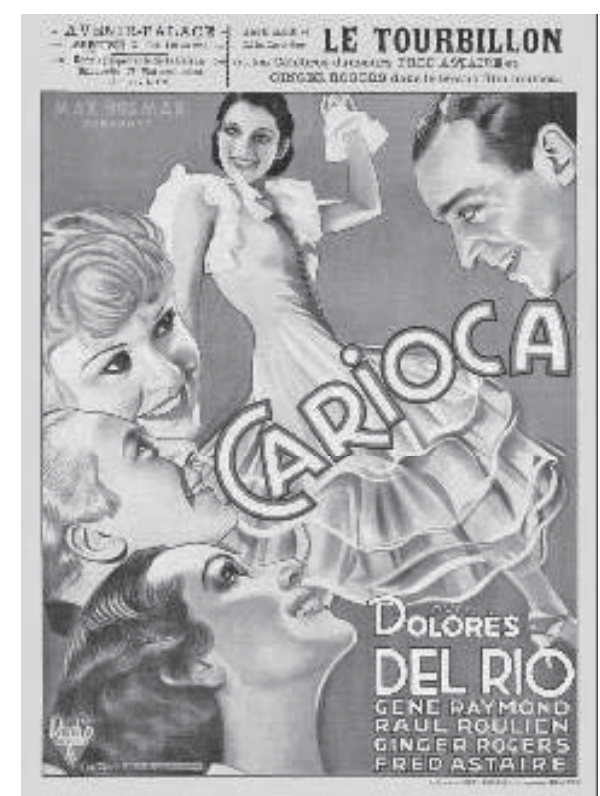

Fig. 1

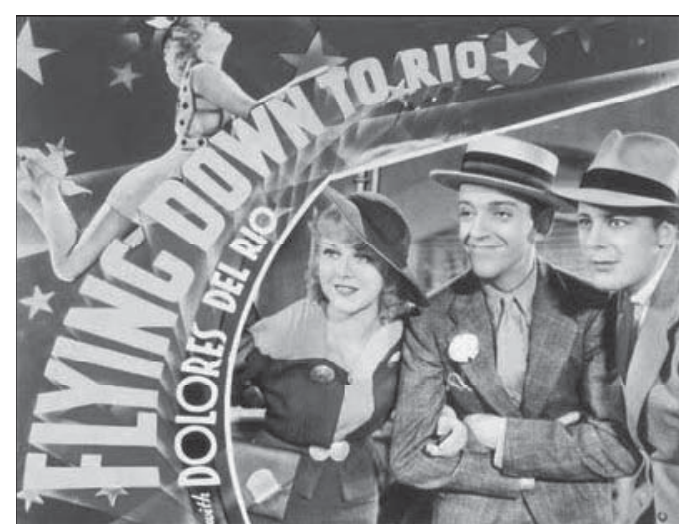

Fig. 2

\footnotetext{
3 Todas las figuras utilizadas en este trabajo provienen de: Internet Movie DataBase. $<\mathrm{http} / / \mathrm{www} . \mathrm{imdb}$. com> Acceso: 12/03/2009. (Flying Down to Rio <http://www.imdb.com/title/tt0024025/> ; Gilda <http://www imdb.com/media/rm1164285952/tt0038559> ; Mexican Spitfire <http:/www.imdb.com/media/rm2623838208/ nm0892473>)
} 
En relación con la mirada como agente reterritorializador, afirma Lacan que,

In our relation to things, in so far as this relation is constituted by the way of vision, and ordered in the figures of representation, something slips, passes, is transmitted, from stage to stage, and is always to some degree eluded in it-that is what we call the gaze (73).

La mirada que se utiliza a lo largo de la película como agente cosificante y que cristaliza en los carteles que se han tomado como ejemplo tiene una doble función: por un lado, responde a lo que Lacan sintetiza como ese agente vehicular que confiere significación a los objetos que observa; por otro lado, sin embargo, la mirada asume una función reivindicativa del sujeto Uno, que afirma su identidad a partir del extrañamiento -la exotización- del objeto Otro.

En este ámbito de producción ideológica a partir de la mirada, el texto fílmico sujeto a estudio se sitúa ante los ojos del público en una posición que lo define y destaca como uno de los puntos de partida de la carrera hacia el estrellato de Fred Astaire -tal y como se apuntaba en la cita señalada en la nota 2- más que como una comedia de estereotipos protagonizada por Dolores del Río en su etapa de estrella al máximo esplendor. La actriz latina que protagoniza este texto fílmico no presenta caracterizaciones de índole ocasional o accidental, tal y como le correspondería a las funciones primordiales de un personaje secundario. Tampoco se halla el actor mencionado cumpliendo un papel de elemento de contraste manifiesto con el de la estrella, ya que aunque sí acepta sus limitaciones, el entorno natural de la estrella se alza en esta película ante su rol subalterno o complementario. Los personajes se ven afectados por la reconfiguración identitaria de la estrella que se produce fuera de plano, fuera de la condición intrínseca a la pantalla que les permite actuar una subjetividad, y que crece potencialmente en detrimento de las jerarquías apriorísticas establecidas a partir del guión original del texto fílmico. El protagonismo fluctúa de forma pendular entre los personajes que son introducidos desde el principio en una relación dialéctica en el ámbito jerárquico de la estructuración. En los momentos de la interpretación musical escénica (de gran relevancia en el apogeo del cine sonoro y como reminiscencia del musical dramático sobre la escena), el protagonismo se cede al actor secundario por definición, que está dando sus primeros pasos dentro del subgénero de baile que él bautizaría, pero que se ve avalado por su importante trayectoria previa en los escenarios de Broadway, de los cuales el musical cinematográfico podría considerarse como una trasposición.

En esta hipótesis confluyen dos argumentos sumergidos: por un lado, se podría establecer una analogía entre la dialéctica ontológica manifestada por este trasvase de poderes subjetivizantes y la formulación casi esotérica de la absorción lumínica con la que ciertos personajes usurpan con su portentoso atractivo -o atracción- la presencia estelar de los actores protagonistas, ralentizando así la capacidad performativa de éstos y refractando en su favor la focalización de la mirada del espectador. En Flying Down to Rio, la actriz mexicana (aunque considerada por la opinión pública estadounidense como europea y de clase alta (Rodríguez-Estrada, 475)) representa la luz menguante, mientras que el actor norteamericano adopta una posición ascendente por medio de un proceso de usurpación del protagonismo de Dolores del Río. Sería, pues, este primer caso un ejemplo de la categoría de personaje secundario que progresa hacia papeles protagonistas partiendo de una

Odisea, $n^{\circ} 11$, ISSN 1578-3820, 2010, 315-327 
presencia accesoria en la trama para terminar adquiriendo la máxima relevancia gracias a una posición étnico-social favorable que privilegia la posición jerárquica elevada del sujeto hombre estadounidense frente a la colocación subalterna del sujeto femenino mexicano como objeto de deseo y de entretenimiento.

Por otro lado, el segundo subargumento en la relación agonista entre estrellas y personajes secundarios es activado a partir de la existencia de una oquedad manifiesta en la lucha por el protagonismo fílmico que debería recaer en Roger Bond, el personaje interpretado por Gene Raymond. Entre los tres personajes se construyen dos niveles diferentes de actuación. Uno, el de los dos hombres, que se discuten el papel protagonista dentro del filme. Otro, el de la estrella efímera que afianza su intermitencias, ya que brilla con fuerza durante un brevísimo periodo de tiempo en el que es admirada por el gran público, para ir después progresivamente diluyéndose en el panorama espectacular de Hollywood, y apagándose hasta no ser más que una imagen perteneciente a un episteme obsoleto, susceptible de sufrir una decrepitud ineludible.

Tras una detenida visualización de esta obra fílmica, se podría afirmar que la dialéctica establecida entre las posiciones de los principales personajes de Flying Down to Rio se debe a una lucha identitaria. El estereotipo de la mujer Latina como estrella ha evolucionado de forma relevante $y$, aunque el gran público estadounidense puede observar potencialidad en la interpretación de Fred Astaire, con la que pueden fácilmente identificarse, su aproximación a la 'estrella exótica latina' no responde a conexiones de identificación, sino de producción de otredad a través de la pantalla. El espectador estadounidense mira su alteridad en Dolores del Río, incapaz de disociar la latinidad que reconfigura sus espacios urbanos con ese personaje Otro que penetra de forma abyecta su espacio doméstico - de familiaridad- a través de la pantalla.

En apoyo de la hipótesis defendida en este estudio, otras dos películas siguen el patrón establecido por Flying Down to Rio en 1933, y aquí serán comentadas brevemente. En 1947 llega a las salas de cine Gilda, dirigida por Charles Vidor y protagonizada por Rita Hayworth y Glenn Ford. Este texto fílmico se asemeja al anterior en que aunque el papel de la estrella no cuenta con ningún otro personaje en función agonística, en este caso se da una evolución del papel del personaje secundario, que se aleja de una posición como 'contra-estrella' para adquirir una condición de ayudante en el desarrollo de la acción, y postularse así como sujeto participante en el mecanismo de énfasis de la figura de la estrella, como personaje en proceso de adquisición de actancialidad que aspira a alcanzar el estatus de estrella y a abandonar su condición de secundario, con lo que afirma en su periférica posición de jerarquía la hegemonía estética de la estrella como centro.

No cabe duda de que en contra de esta manifestación se puede argumentar que la figura de Gilda (y la de Rita) dista estética y epistemológicamente de la figura de Dolores del Río. En la cúspide de la carrera de Hayworth que representa Gilda, la protagonista no se ve asediada por miradas que intenten subjetivizar su identidad, porque el proceso de reescritura de su cuerpo a modo de palimpsesto ya ha sido llevado a cabo por ella misma, ya que como afirma Adrienne McLean en gran parte de su ensayo Being Rita Hayworth: labor, identity, and Hollywood stardom, la actriz hija del bailaor de flamenco español Eduardo Cansino se ocupa durante la etapa más temprana de su carrera de borrar de su identidad todo rasgo latino que la limite a papeles secundarios o reificantes, y cuando protagoniza Gilda se ha 
convertido-físicamente- en una estrella que responde a todos los parámetros marcados por Hollywood para ocupar tal posición: se ha centrado en la limpieza de su imagen de rasgos latinos por medio de una dolorosa electrólisis para ensanchar su frente y marcar la forma de su pelo hasta convertirse en una pelirroja cuyo nombre ya no era Margarita Cansino, sino Rita Hayworth. El proceso de cosificación se ha completado en la forma de una identidad superpuesta que renuncia a su condición de latina para responder a las exigencias del manual de la estrella de Hollywood, pero será esa capacidad de actuar como sujeto actancial un rasgo que la actriz arrastrará a lo largo de su carrera y que le permitirá alejarse de la pasividad performativa que se le supone a la mujer de la época dorada de Hollywood para identificarse con una revisión de la mujer fatal del cine negro que deconstruye las miradas cosificantes masculinas para convertirlas en juguetes de sus actuaciones:

In a brief unpublished essay called 'A Femme Fatale Communicates through Dance,' dance scholar Svea Becker states that by her dancing 'Gilda (and Rita Hayworth) escapes the confines of the noir formula which is defined by masculine rules, including physical mastery of the environment.' As an act of freedom, dancing allows Gilda physically to assert herself and thus to overcome the 'passive feminine stereotype' (McLean, 160)

El dispositivo de identificación a través de la mirada se manifiesta en Gilda a partir de los personajes secundarios que se discuten la primacía de la mirada de Gilda. En su actuación, la protagonista de este texto fílmico no decae en una mirada inerte que se proyecta como reflejo de la mirada masculina, sino que adquiere plena subjetividad e intimida las miradas de quienes tratan de deconstruir su identidad (tanto personajes secundarios como espectadores), no permitiéndoles ser partícipes de una transformación identitaria sobre la que ella y sólo ella tiene poder (fig. 3). Por este motivo, los personajes secundarios que la rodean debaten con la estrella sus posiciones, pero nunca de forma subversiva como sucedía en Flying Down to Rio, sino como ratificación del poder discursivo y performativo de Gilda como estrella indiscutible. Rita Hayworth (y Gilda) es una mujer cuya actancialidad para reescribir su cuerpo la ha dotado de una 'americanidad' por un lado (su apariencia física y su condición como mujer que se construye a sí misma) y de una 'masculinidad' por otro lado (se postula a sí misma como sujeto, nunca como objeto) que afianza su identidad como intimidatoria para las miradas que en otros casos amenazaban su posición. Ya no se trata de que los personajes secundarios dejen de lado una intención usurpadora, sino que ahora toman 'consciencia de clase' y tratan a la estrella no como a un objetivo ontológico, sino como a una instancia necesaria para alcanzar su desarrollo pleno como personajes secundarios.

Odisea, $\mathrm{n}^{\circ} 11$, ISSN 1578-3820, 2010, 315-327 


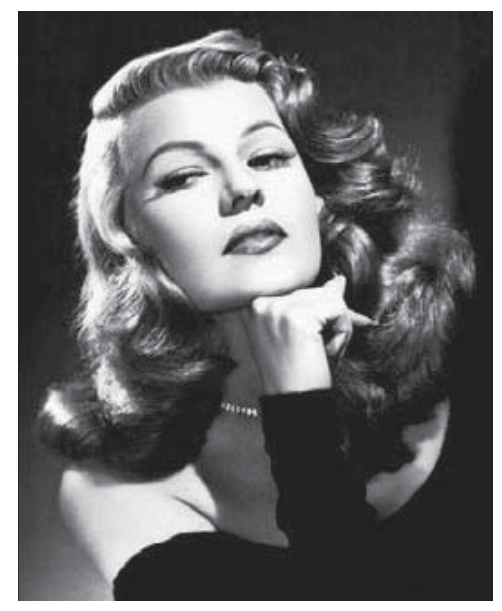

Fig. 3

La dialéctica intratextual se produce así entre personajes cuyas aspiraciones no pasan por eclipsar el protagonismo de Gilda, sino que ofrecen a partir de su falta de integridad interpretativa y argumental la consolidación de Gilda como estrella, a la vez que afirman la trascendencia de su papel como secundarios para el desarrollo completo de la figura protagonista. En ese devenir dialéctico la estrella puede reafirmar su idiosincrasia, utilizando como instrumento de producción identitaria la definición de su subjetividad que proyecta a partir del personaje secundario.

El tercer ejemplo para tratar la presencia de los personajes secundarios como entes activos en el desarrollo discursivo de la estrella es la serie de Mexican Spitfire (1939-1943), dirigida por primera vez en 1939 por Leslie Goodwins con el título de The Girl from Mexico y contando entre sus estrellas con la actriz mexicana Lupe Vélez, que interpreta a Carmelita Lindsay, una artista latina de carácter temperamental. La serie de Mexican Spitfire, y en concreto la segunda película de título homónimo al de la serie (1940), es susceptible de plasmar en sus diálogos e interpretaciones las características y el funcionamiento del sistema estelar que dio forma al cine de Hollywood de los años 30 y 40 . Lupe Vélez da vida a un estereotipo, el de la 'mujer latina irreductible', y se opone a una serie de personajes que son también definidos a partir de configuraciones tipológicas que legitiman una visión maniquea de la realidad, haciendo de ellos la norma y del personaje femenino mexicano la perversión de esa norma:

The signification of [Latina] women exists through and against Western constructions of Latina femininity, Latina sexuality, white feminine purity, and nonerotic sexuality, such as motherhood, and simultaneously as dangerously impure racialized bodies with uncontrollable emotions and sexual desires, such as the Latina Spitfire. (Mendible, 235)

Estas palabras de Myra Mendible (aunque en su caso referidas al caso de las mujeres cubanas o cubano-americanas) reflejan la actitud condescendiente del espectador de Mexi- 
can Spitfire, que se siente contradictoriamente seducido y agredido por la irracionalidad de Lupe Vélez interpretándose a sí misma a través de Carmelita Lindsay (fig. 4). Tal y como lo expone Rodríguez-Estrada:

'In her eighteen-year career in Hollywood, Velez consciously chose and groomed her image as 'Whoopee Lupe,' the 'Hot Tamale,' and 'Hot Pepper.' With her proclamation, 'I am not wild. I am just Lupe,' Velez developed a public reputation as the 'Hot Baby' of Hollywood and found herself in roles portraying 'half-castes' and 'exotic' characters. (476)

En el caso del film de Goodwins, el mecanismo que activa la relación entre la estrella y el personaje secundario se aleja del que se manifestará años después en Gilda mediante una propuesta de ensalzamiento estelarizado por medio de la afirmación del secundario como tal, y tenderá a invertir tal proceso para que el espectador encuentre al personaje de Carmelita Lindsey como abyecto, cosificado y muy alejado de la condición normativizada con la que se siente identificado. Muy al contrario, la condición de estrella de Lupe Vélez estará siempre asociada al carácter indómito de su personaje de ficción, por lo que cualquier desavenencia entre ambas representaciones será criticada por la opinión pública. Cuando Vélez se casa con Weissmuller su imagen pasa de ser la de una fiera indómita a ser satirizada como la de un ama de casa sumisa, lo cual repercute directa y negativamente en su carrera artística y en su condición de estrella, ya que el deseo de 'domesticar' a esa fiera mexicana que comparten las miradas desde la butaca desaparece con su 'consecución' por parte del actor estadounidense, y las múltiples referencias a la violencia doméstica perpetrada por éste contra la actriz mexicana redundan en la visión condescendiente del espectador hacia Vélez.

Espectador implícito y espectador empírico confluyen en una reacción de ira, burla y deseo ante la vehemente actriz mexicana, y los personajes que arropan a esta estrella albergan de nuevo una función complementaria, con la diferencia de que ahora su principal objetivo es el de ensalzar las características connotativas que el público a quien va dirigida la obra entiende como negativas. Aquellos personajes que actúan, sin embargo, las tipologías que se corresponden con el imaginario estadounidense se alejan ostensiblemente de las posibles identificaciones caricaturizantes con la polémica escupefuego, y se sitúan próximos a una mimetización con la reconfiguración masculinizante y etnocéntrica del estadounidense que ve a la mujer norteamericana como figura desdeñosa y desapacible, pero que alienta unos valores encomiables y respetados, mientras que la honestidad y la franqueza de la protagonista mexicana son entendidos como rasgos de simpleza y de poco valor moral. A pesar de que en ciertos momentos de la película, la estrella ridiculizada adquiere un cierto estatus de respeto, su condición marginal no desaparece más que cuando su personaje se somete a un proceso de 'americanización', proceso que estará esencialmente condenado al fracaso, ya que la personalidad que se ha labrado en su escalada hacia la fama no le permite asimilarse -como sí haría Rita Hayworth- con los valores comedidos del 'savoirfaire' estadounidense. Los personajes secundarios empujan de esta forma al espectador implícito a compartir con ellos una complicidad en la que adquieren una función vehicular 
para ratificar la parodia del -a sus ojos-caricaturesco personaje de Lupe Vélez, cuya losa de Sísifo es su propia escritura identitaria.

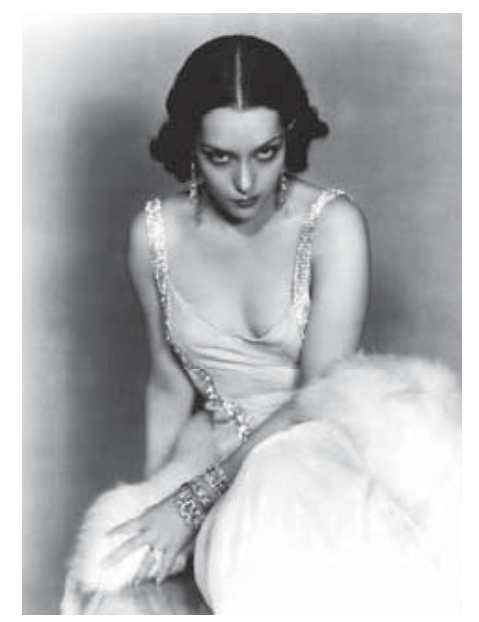

Fig. 4

Así pues, la función estelar de la figura latina se manifiesta abiertamente de manera reificada, y parece distanciarse de las necesidades actanciales que sí reclamaban Dolores del Rio o Rita Hayworth. La estrella se halla perimetrizada por los efectos reafirmantes que han tenido en el gran público de Hollywood sus celebraciones de la latinidad estereotipada y se ha encontrado en un bucle de entropías alienantes que ayudaron a la desintegración de su subjetividad y a la imposibilidad de lidiar con tal fragmentación. Su privación de autodeterminación actancial pervirtió su condición de estrella hasta convertirla en una parodia de sí misma.

Tras haber analizado los casos de estas tres estrellas latinas en el Hollywood de las décadas de los años 30 y 40 , se puede concluir afirmando la importancia máxima que tuvo la aparición del fenómeno estelar en el cine de esa época, pero no menos el también relevante -y complementario-surgimiento de los personajes secundarios como ayudantes, oponentes o propiamente objetos de la configuración performativa estelarizada. Siguiendo el esquema de Greimas, la incorporación del elemento estelar que se sitúa en un espacio fronterizo entre la actuación artística y la performance biográfica problematiza la unidimensionalidad de su propuesta, y complica el plano diegético al ser éste penetrado por una paratextualidad con poder actancial ('powers of agency').

No es objetivo primordial de este estudio, no obstante, analizar los rasgos significantes de los participantes en el proceso comunicativo cinematográfico - aunque sería arriesgado desdeñar la importancia de este factor en la distribución actancial del texto fílmico. Este estudio se centra en la observación -y el cuestionamiento- del entorno estético en el que la 
maquinaria de producción identitaria se halla al (re)escribir la capacidad de actuación de la estrella y del personaje secundario, tarea fundamental para reinterpretar las relaciones actanciales entre la industria cinematográfica y sus proyecciones al otro lado de la pantalla.

\section{REFERENCIAS BIBLIOGRÁFICAS:}

Ansón, Antonio, 1994. El Istmo de las luces (Madrid: Cátedra).

AugÉ, Marc, 2008. Non-places: Introduction to an Anthropology of Supermodernity (London; New York: Verso).

Barthes, Roland, 1977. Image, Music, Text (New York: The Noonday Press).

Beltrán Mary C, 2005. 'The New Hollywood Racelessness: Only the Fast, Furious, (And Multiracial) Will Survive' Cinema Journal, 44.2: 50-67

Cartwell, D. \& Wheleham, I. (ed.), 1999. Adaptations (New York: Routledge).

CASSETtI, Francesco,1998. Inside the Gaze: the fiction film and its spectator (Indianapolis: Indiana University Press).

Doherty, Thomas, 1999. Pre-Code Hollywood: Sex, Immorality, and Insurrection in American Cinema; 1930-1934 (New York: Columbia University Press).

Dyer, Richard, 1998. Stars (London: BFI).

EAsthope, Anthony, 1991. Literary into Cultural Studies (NY: Routledge).

FLYING Down to RIO, 1933. Dir. Thornton Freeland. Perf. Dolores del Rio, Gene Raymond, Ginger Rogers, and Fred Astaire (RKO).

Genette, Gerard, 1997. The work of art (NY: Cornell University Press).

GILDA, 1947. Dir. Charles Vidor. Perf. Rita Hayworth, Glenn Ford, George Macready, and Joseph Calleia (Columbia Pictures Corporation).

Greimas, Algirdas y Courtés, Joseph, 1991. Semiótica/ Semiotics. Diccionario razonado de la teoría del lenguaje (Madrid: Gredos).

Guzzetti, Alfred, 1973. 'Christian Metz and the Semiology of the Cinema'. Journal of Modern Literature 3.2: 292-308.

Hetherington, Kevin, 1997. The Badlands of Modernity: Heterotopia and Social Ordering (London and New York: Routledge).

JACoBs, LewIs, 1969. The Emergence of Film Art. The Evaluation and Development of the Motion Picture as an Art from 1900 to the Present. (New York: Hopkinson \& Blake).

Konigsberg, Ira, 1993. The complete film dictionary (Ontario: Nal Books).

LaCan, Jacques, 1978. Escritos (México: Siglo XXI). 
1998. The Four Fundamental Concepts of Psycho-Analysis (New York: W. W. Norton \& Company).

Loukides, Paul; Fuller, Linda (EDS.), 1990. Beyond the Stars. Themes and Ideologies in American Popular Film (Ohio: Bowling Green State University Popular Press).

McClure, Arthur (ED.), 1971. The Movies: an American Idiom; Readings in the Social History of the American Motion Picture (New Jersey: Fairleigh Dickinson University Press).

McLean, Adrienne, 2004. Being Rita Hayworth: Labor, Identity, and Hollywood Stardom (New Jersey: Rutgers University Press).

Mendible, Myra, 2007. From Bananas to Buttocks: the Latina Body in Popular Film and Culture (Austin: University of Texas Press).

MEXICAN SPITFIRE, 1940. Dir. Leslie Goodwins. Perf. Lupe Vélez, Donald Woods, and Linda Hayes (RKO).

Mueller, John, 1986. Astaire Dancing - The Musical Films (London: Hamish Hamilton).

Noremore, James, 1988. Acting in the Cinema (Berkeley: University Press).

Rodríguez-Estrada, Alicia, 1997. 'Dolores del Rio and Lupe Velez: Images on and off the screen, 1925-1944', en Writing the range: race, class, and culture in the women's West, eds. Elizabeth Jameson y Susan Hodge Armitage, Norman: University of Oklahoma Press (475-492).

Romera, J. Nicolás; Yllera, Alicia (eds.), 1993. Semiótica(s) Homenaje a Greimas (Madrid: Visor).

Seldes, Gilbert, 1970. The Great Audience (Greenwood Press).

SAYre, Henry, 1989. Object of Performance (Chicago: University of Chicago Press).

Williams, Alan, 1992. Structures and narrativity in Fritz Lang's Metropolis (Cambridge: Harvard University Press).

Williams, LindA, 1995 'Corporealized Observers: Visual Pornographies and 'the Carnal Density of Vision', en Fugitive Images: From Photography to Video, ed. Patrice Petro, Bloomington: Indiana University Press (3-37). 